\title{
An Analysis of Appraisal in CEO Corporate Social Responsibility Statements
}

\author{
Dongmei Wang \\ Department of Foreign Languages, Dalian University of Technology, 116024, Dalian, China \\ Xiaowei Guan \\ Department of Foreign Languages, Dalian University of Technology, 116024, Dalian, China
}

\begin{abstract}
This article employed Appraisal theory in a comparative analysis of two CEO statements in BP's 2009 Sustainability Review and BP's 2011 Sustainability Review respectively. The main objective is to explore how, through Appraisal resources, the leaders of a company, when facing a disastrous accident, constructed their corporate identity and relationship with the stakeholders. The analysis reveals that the appraisal resources in 2011 CEO statement played a major role to help the CEO portray the company as a survivor from a disaster, a good learner getting stronger from a painful lesson and a trustworthy helper providing energy to the whole world.
\end{abstract}

Index Terms - appraisal, corporate social report, CEO statement, discourse analysis

\section{INTRODUCTION}

Corporate social responsibility (CSR) is one of the most often-discussed topics in the field the management, and scholars have different understandings on it. In 1953 Howard R. Bowen published the book titled Social Responsibilities of the Businessman, which is considered to be the one that started the researches on this concept. According to Bowen $(1953$, p. 6), the social responsibility of businessmen "refers to the obligations of businessmen to pursue those policies, to make those decisions, or to follow those lines of action which are desirable in terms of the objectives and values of our society". Today, more than 50 years after Bowen set forth this definition on CSR, "businesses operate in a climate of intense public scrutiny, where stakeholders expect that corporations and industries accept accountability for the social and environmental implications of their operations" (Deegan et al, 2000, p. 101). Therefore, a new form or genre of institutional discourse, corporate social responsibility report, came into being. By releasing information about the influences their operations may exert on the society, organizations could respond to "society's heightened sensitivity to the externalities of business activities" (Ullmann, 1985, p. 540). Most of the CSR reports present a statement by the CEO, and maybe it is because CEOs are "literally and symbolically the organization in the eyes of the stakeholders" (Park \& Berger, 2004, p. 93). In the context of CSR reports, the CEO's statement represents the corporate position on CSR activities, seeks to persuade stakeholders to follow the CSR direction outlined and shape a favorable corporate image (Waldman, Siegel \& Javidan, 2006, p. 1704). The present study chose two CEO corporate social responsibility statements as samples. The two texts are from British BP company's Sustainability Review 2009 and Sustainability Review 2011. As we know, in 2010 a BP oil well broke and sent thousands of gallons of crude oil into the Gulf of Mexico, causing one of the most serious environmental catastrophes in the history. So we intend to compare the CEO's statements before and after the disaster to explore how the leaders of an organization use justificatory discursive strategies to legitimize their operations after perceived episodes of wrongdoings. Appraisal Theory was employed to analyze the interpersonal language resources in the two texts. The analysis aims to address the following questions: a) What kind of evaluative resources are used in the two CEO statements to construct the company's identity? b) What kind of relationship do they establish with the stakeholders?

\section{APPRAISAL THEORY}

Appraisal Theory is developed as one important concept within Systemic Functional Linguistics. From the 1980s the researchers in the Write It Right project of the NSW Disadvantaged Schools Programs tried to find out " the literacy requirements of the discourses of science, technology, the media, history, English literature studies, geography and the visual arts" (Iedema, Feez, and White, 1994). The findings of this project laid the foundation of Appraisal Theory, which is now considered to be an extension of one of the meta-functions in Systemic Functional Linguistics: interpersonal meta-function. In SFL, language is considered to be a semiotic system with three levels of abstraction. Martin and White (2005, p. 10) claim that appraisal should be located at the level of discourse semantics. They have provided three reasons for this point of view. Firstly, attitude can be realized in different phases of a discourse. Secondly, attitude can be realized by different grammatical categories. Thirdly, grammatical metaphor illustrates well that appraisal belongs to discourse semantics. 


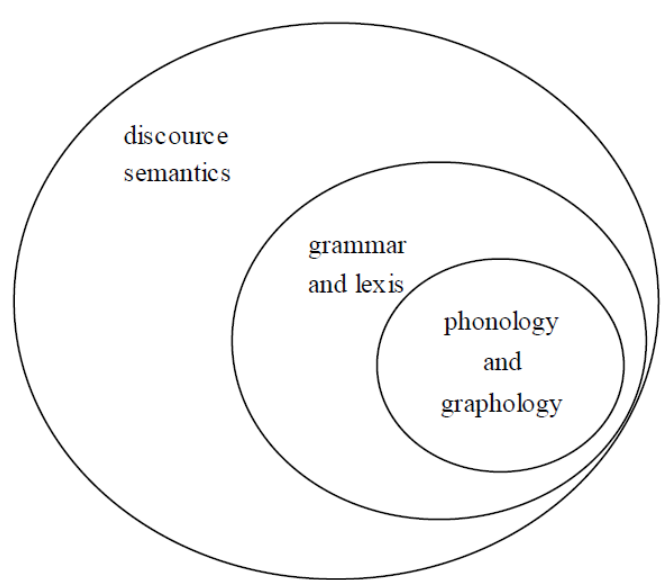

Figure I. Language strata (Martin \& White 2005)

According to Martin \& White, "appraisal is concerned with evaluation: the kinds of attitudes that are negotiated in a text, the strength of the feelings involved and the ways in which values are sourced and reader aligned" (2005, p. 22). To examine the three parts of appraisal, three systems have been set up in Appraisal Theory: attitude, engagement and graduation. In this paper, we just cover the first two systems when discussing appraisal across the two CEO statements.

\section{A. Attitude}

According to Martin \& White (2005), in the system of meanings labeled as attitude, three semantic categories are involved. They refer to the concepts of emotion, ethics and aesthetics respectively. In Appraisal Theory, this emotive dimension of meaning is referred to as AFFECT. AFFECT is about human beings' feelings. In Appraisal Theory, AFFECT can be illustrated by lexical items mentioned in the following table.

TABLE I.

LEXICAL REALIZATION OF AFFECT (MARTIN \& WHITE, 2005)

\begin{tabular}{|l|l|l|}
\hline Affect & Positive & Negative \\
\hline dis/inclination & miss, long for, yearn for & wary, fearful, terrorized \\
\hline un/happiness & cheerful, jubilant, love, like & sad, sorrowful, dejected, low, weepy \\
\hline in/security & confident, assured, comfortable & uneasy, anxious, surprised, astonished \\
\hline dis/satisfaction & involved, pleased, impressed, thrilled & stale, angry, furious, bored with \\
\hline
\end{tabular}

The ethics dimension of meaning is referred to as JUDGEMENT. JUDGEMENTS can be classified into the sub-system that is concerned with "social esteem" (how unusual, how capable, or how resolute one is), and the sub-system that is concerned with "social sanction" (how truthful, or how moral someone is). JUDGMENT can be illustrated by lexical items mentioned in the following table.

TABLE II.

LEXICAL REALIZATION OF JUDGMENT (MARTIN \& WHITE, 2005)

\begin{tabular}{|l|l|l|}
\hline Judgment & Positive & Negative \\
\hline normality & lucky, normal, stable, familiar... & unlucky, odd, peculiar, obscure... \\
\hline capacity & powerful, fit, experienced, clever... & weak, sick, immature, stupid... \\
\hline tenacity & brave, patient, resolute, reliable... & cowardly, impatient, distracted... \\
\hline veracity & truthful, honest, credible, candid... & deceitful, manipulative, blunt... \\
\hline propriety & moral, ethical, fair, kind, caring... & bad, evil, vain, snobby... \\
\hline
\end{tabular}

The aesthetics dimension of meaning is referred to as APPRECIATION. APPRECIATION can be further divided into three smaller categories: reaction, composition, and value. APPRECIATION can be illustrated by lexical items mentioned in the following table.

TABLE III.

LEXICAL REALIZATION OF APPRECIATION (MARTIN \& WHITE, 2005)

\begin{tabular}{|l|l|l|}
\hline Appreciation & Positive & Negative \\
\hline reaction(impact) & arresting, engaging, remarkable... & dull, uninviting, unremarkable... \\
\hline reaction(quality) & fine, lovely, splendid, welcome... & bad, nasty, plain, repulsive.... \\
\hline composition(balance) & balanced, harmonious, consistent... & unbalanced, irregular, uneven... \\
\hline composition(complexity) & simple, pure, clear, precise... & ornate, arcane, unclear, plain... \\
\hline valuation & original, deep, innovative... & shallow, reductive, conventional... \\
\hline
\end{tabular}

\section{B. Engagement}

The system of engagement is about the linguistic resources which make it possible "for the authorial voice to position 
itself with respect to, and hence to 'engage with', the other voices and alternative positions construed as being in play in the current communicative context" (Martin \& White, 2005, p. 94). In Appraisal Theory, engagement system is described in the following way:

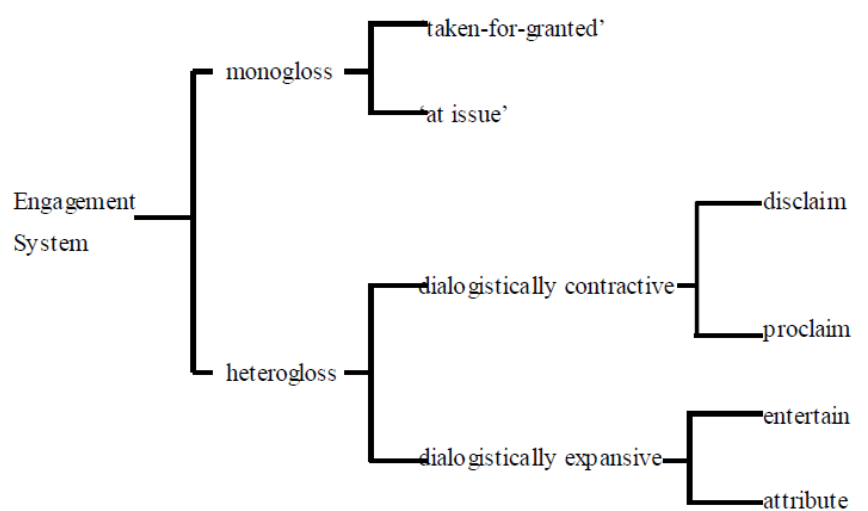

Figure II. Engagement: monogloss and heterogloss (Martin and White, 2005)

The concept of engagement in Appraisal theory is encouraged by Bakhtin's notions of 'heteroglossia' and 'intertextuality' $(1981,1986)$. When discussing these terms, Bakhtin suggests that all texts are dialogistic in nature, which means that all texts have to interact with other texts.

The desire to make one's speech understood is only an abstract aspect of the speaker's concrete and total speech plan. Moreover, any speaker is himself a respondent to a greater or lesser degree. He is not, after all, the first speaker, the one who disturbs the eternal silence of the universe. And he presupposes not only the existence of the language system he is using, but also the existence of preceding utterances--his own and others'--with which his given utterance enters into one kind of relation or another (builds on them, polemicizes with them, or simply presumes that they are already known to the listener). Any utterance is in a very complexly organized chain of other utterances. (Bakhtin, 1986, p. 69)

\section{METHODOLOGY}

The present study is a corpus-driven discourse analysis. With Appraisal Theory as its theoretical framework, corpus linguistics analysis techniques were employed to provide quantitative results for researchers' qualitative interpretation. Corpus linguistics studies real-life language use on the basis of textual data, and organizational documents like CEO statements in CSR reports are real-life, naturally occurring materials. This study presents a comparative analysis of appraisal resources in two CEO statements from BP's Sustainability Review 2009 \& Sustainability Review 2011. The main features of the two texts are summarized in the following table.

TABLE IV.

CORPUS DETAILS

\begin{tabular}{llc}
\hline Text & Tokens & Types \\
\hline BP2009 CEO statement & 1561 & 642 \\
\hline \hline BP2011 CEO statement & 1172 & 516 \\
\hline
\end{tabular}

Corpus linguistics analysis tool Wordsmith 5.0 was used to conduct the quantitative research, which was focused on the sub-system of ATTITUDE and ENGAGEMENT. As far as ATTITUDE is concerned, the present study only analyzed the explicit instances (inscription). Implicit instances (token) were not considered because tokens "assume shared social norms...they are highly subject to reader position, and each reader will interpret them according to their own cultural and ideological positioning" (White, 2001, p. 3-4). As for as ENGAGEMENT is concerned, the study classified the instances of ENGAGEMENT into a contractive group and an expansive group. By using Engagement resources, the speakers or writers can engage themselves. The Engagement resources can be divided into those that open up the dialogue and those that try to close down the dialogue (White, 2001, p. 8). White argues that ENGAGEMENT resources could be considered as "lying along a cline between what most contracting and most expanding" (White, 2001, p. 10).

The analysis of ATTITUDE and ENGAGEMENT is based on the computer-aided manual annotation of the two texts. The annotation was performed on tokenized texts. Instances judged by the analysts as AFFEDCT were marked as [X1], instances judged by the analysts as JUDGEMENT were marked as [X2], and instances judged by the analysts as APPRECIATION were marked as [X3]. The ENGAGEMENT instances that were considered to be more contractive were marked as [Y1], while those that were considered to be more expansive were marked as [Y2]. After the training session where the annotators were informed of the criteria for coding the five categories mentioned above, we conducted a reliability test to insure bias and subjectivity in the marking process of the instances are controlled. The reliability test method is illustrated in Table 5. And the result shows that both of the two inter-agreement tests (for 2009 
CEO statement and for 2011 CEO statement) are above $80 \%$, which indicates that the level of agreement is acceptable.

TABLE V.

INTER-CODER AGREEMENT TEST RESULT FOR 2009 CEO STATEMENT

\begin{tabular}{|l|l|l|l|l|l|}
\hline $\begin{array}{l}\text { Classification of appraisal resources } \\
(09 \text { CEO statement) }\end{array}$ & Instance 1 & Instance 2 & $\ldots$ & instance 49 \\
\hline A AFFECY & 1 & 0 & $\ldots$ & 1 & inter-coder agreement \\
\hline B JUDGEMENT & $\ldots$ & $\ldots$ & $\ldots$ & $\ldots$ & $\ldots$ \\
\hline C APPRECIATION & $\ldots$ & $\ldots$ & $\ldots$ & $\ldots$ & $\ldots$ \\
\hline D CONTRACTION & $\ldots$ & 1 & $\ldots$ & 1 & $\ldots$ \\
\hline E EXPANSION & 1 & $\ldots$ & & $\ldots$ \\
\hline result & & & & $\ldots$ \\
\hline
\end{tabular}

\section{RESUlTS}

The results of the analysis show significant differences in the use of appraisal resources in the two CEO statements. Examination of the 20 most frequent instances of ATTITUDE in the two texts shows that in 2009, BP's biggest mission is to operate sustainably at the frontier of the oil industry; and the strategic priority lies in providing reliable and affordable energy to meet the world's increasing demand. In sharp contrast, the message sent out from the CEO statement in 2011 CSR report reveals that the priorities set by the company in this year are to draw lessons from the accident, enhance its safety management, earn back trust, and make BP a safer and stronger corporation.

TABLE VI.

ATTITUDE INSTANCE: WORDLISTS

\begin{tabular}{|c|c|c|c|c|}
\hline $\mathbf{N}$ & Word(2009) & $\%$ & Word(2011) & $\%$ \\
\hline 1 & $S A F E$ & 4.977375507 & SUSTAINABLE & 4.624277592 \\
\hline 2 & HIGH-CONSEQUENCE & 4.298642635 & SIGNIFICANT & 4.335259914 \\
\hline 3 & CHALLENGE & 3.619909525 & KEY & 4.046242714 \\
\hline 4 & SUSTAINABLE & 3.393665075 & SAFE & 4.046242714 \\
\hline 5 & SIGNIFICANT & 3.167420864 & ADVANCED & 3.468208075 \\
\hline 6 & AVAILABLE & 2.941176414 & MAJOR & 3.468208075 \\
\hline 7 & KEY & 2.941176414 & EFFICIENT & 3.179190636 \\
\hline 8 & ENHANCED & 2.714932203 & CHALLENGE & 2.890173435 \\
\hline 9 & STRONG & 2.488687754 & EFFECTIVE & 2.601155996 \\
\hline 10 & GOOD & 2.036199093 & RESPONSIBLE & 2.601155996 \\
\hline 11 & IMPORTANT & 2.036199093 & RELIABLE & 2.312138796 \\
\hline 12 & CLEAR & 1.809954762 & BEST & 2.023121357 \\
\hline 13 & COMPLEX & 1.809954762 & DIVERSE & 2.023121357 \\
\hline 14 & PRIORITY & 1.809954762 & IMPORTANT & 2.023121357 \\
\hline 15 & BEST & 1.583710432 & AVAILABLE & 1.734104037 \\
\hline 16 & ESSENTIAL & 1.583710432 & CLEAR & 1.734104037 \\
\hline 17 & NECESSARY & 1.583710432 & FRONTIER & 1.734104037 \\
\hline 18 & RELIABLE & 1.583710432 & RIGHT & 1.734104037 \\
\hline 19 & RIGHT & 1.583710432 & GOOD & 1.445086718 \\
\hline 20 & SENSITIVE & 1.583710432 & AFFORDABLE & 1.156069398 \\
\hline
\end{tabular}

Within the system of ATTITUDE, the Chi-Square calculator reveals that some of the sub-systems are significantly different between the two texts.

TABLE VII.

SUB-SYSTEMS OF ATTITUDE: CHI-SQUARE TEST RESULT

Chi-Square Calculator

\begin{tabular}{|c|c|c|c|c|c|}
\hline Corpus Size: [ & $\begin{array}{r}\text { Corpus } 1 \\
\qquad 1,561\end{array}$ & & $\begin{array}{r}\text { Corpus } 2 \\
1,172\end{array}$ & & \\
\hline Word & Freq in Corpus 1 & Freq in Corpus 2 & Chi-Square & Significance $(p)$ & \\
\hline $\operatorname{AFFECT}(+)$ & 4 & 7 & 1.9420 & 0.163 & - \\
\hline AFFECT(-) & 2 & 9 & 6.8355 & $0.009^{* *}$ & - \\
\hline JUDGEMENT(+) & 4 & 15 & 10.1597 & $0.001^{* *}$ & - \\
\hline JUDGEMENT(-) & 0 & 0 & & & \\
\hline APPRECIATION $(+)$ & 5 & 9 & 2.6317 & 0.105 & - \\
\hline APPRECIATION(-) & 6 & 13 & 5.0945 & $0.024^{*}$ & - \\
\hline
\end{tabular}

The amount of the authorial AFFECT in 2011 CEO statement outnumbers that in 2009 CEO statement. In 2009 CEO statement, the positive authorial AFFECT instances include: WANT (indicating inclination), CONFIDENCE (indicating security), and PROUD (indicating satisfaction). These words with emotional dispositions are all expressed in the first person, suggesting the company's desire to achieve positive goals in its future operation and management.

For example:

(1) I want this to be a place where everyone can fulfill their potential. 
(2) We have emerged from 2009 in great shape and with a renewed confidence and determination to realize our potential both in the short and the long term.

(3) I'm proud that our injury rates have come down around $75 \%$ in the past decade.

In 2011 CEO statement, the positive authorial AFFECT include CARE, THRIST (indicating inclination), HEARTENED, PLEASED (indicating satisfaction), and ENCOURAGED (indicating security). These positive emotional words suggest that BP is willing to learn from the accident, earn back trust and deliver more value to the stakeholders. And until now, their remedy work has had an effect. The American government has approved that BP could resume its drilling and, by year-end, they have had five rigs running.

For example:

(4) We care about the safe management of the environment.

(5) We commit to quality outcomes, have a thirst to learn, and to improve.

(6) I am heartened that visitors have returned, with some areas reporting record seasons.

(7) We were pleased to receive the go-ahead from the US government to resume drilling and, by year-end, we had five rigs running.

(8) $\mathrm{BP}$ is encouraged by local and state reports that indicate tourism in many areas of the region is rebounding.

The difference in the sub-category of negative authorial AFFECT is significant between the two texts $(p=0.009)$. In the CEO statement of 2011, the most frequently used negative word is CONCERN. With the help of KWIC searches, we found this word is more likely to collocate with words that have negative connotations. It's not difficult to imagine the harsh criticism BP had to face from the stakeholders after the disaster. The following sentence appears in the statement with "deliver value, meet needs" as its main topic.

(9) While we feel a strong responsibility to help meet this growing demand, we also share wide-spread concerns about the rising global $\mathrm{CO} 2$ emission levels that it implies.

The use of pronoun "we", the verb "help" and "share" helps establish an image for the company. We are the provider of energy who helps the whole world the meet its increasing need of energy (this is a common sense). In order to meet "your" needs, "we" exist to help. So in other words, our existence and operation are indispensible and moral because we have improved people's life and impacted positively on the world. By distancing itself from other stakeholders, and by depicting itself as a provider and helper, this statement successfully justified BP's operation, even the whole oil industry's operation.

In the sub-system of JUDGEMENT, no negative JUDGEMENT resources were used in the two CEO statements in the year of 2009 and 2011. There are more positive JUDGEMENT resources in the 2011 CEO statement than that of 2009. Both of the two statements feature the positive self-evaluations like "EXPERT", "EFFICIENT", "RESPONSIBLE", "PERFORMANCE-DRIVEN", "INNOVATIVE", and "PIONEERING". All of these words help depict BP as a moral, capable, and responsible pioneer company in the oil industry. With further analysis, we found that among all the positive JUDGEMENT resources, only the frequency difference of the word "STRONG" is statistically significant between the two statements $(p=.023)$. And the comparative form of the word is the only form in which the word appeared. The word "STRONGER" can be interpreted as message BP wants to send the public: we have learnt a lot from the disaster, so we will be a stronger one in the future. In this sense, positive JUDGEMENT resources not only help the organization defend itself in face of crisis, but also fulfill a promotional function with self-praising.

For example:

(10) 2011 was a year of recovery, consolidation and change for BP. Our employees worked hard to make BP a stronger, safer company.

(11) I believe that by helping to meet the world's energy needs in a responsible and sustainable way, a stronger and safer BP will be a powerful contributor to growth and progress.

In the sub-system of APPRECIATION, the frequency difference of the negative APPRECIATION is found to be statistically significant. With the help of KWIC searches, researchers found that all the negative APPRECIATION resources are used to depict the problems the whole oil industry has to face to: oil industry is a hazardous business, so it is challenging for us to provide energy to meet the ever increasing need in a secure and efficient way.

For example:

(12) We are in a hazardous business, and are committed to excellence through the systematic and disciplined management of our operations.

(13) Over time, the available hydrocarbon resources will become increasingly difficult to reach, extract and manage, requiring $\mathrm{BP}$ and others in our industry to move into more technically-challenging areas.

(14) Deepwater drilling; unconventional gas; oil sands; giant fields - there are tough technical, environmental and social challenges ahead in every area.

Surprisingly, in the 2011 CEO statement, there're no negative evaluations on the consequences of the oil spill disaster at all. The following sentence is the only sentence talking about the accident.

(15) This was a complex accident that involved multiple parties and had multiple causes.

Putting the sentence in a bigger context, the researchers found that it is about the investigation result from some external investigations: This accident is complicated because it had multiple causes and many parties got involved. So the seemingly negative APPRECIATION "complex" can be interpreted as a justificatory wording to the interest of BP 
company. Another interesting word whose frequency difference is found to be statistically significant $(p=.033)$ is "HIGH-CONSEQUENCE". Just like the word "COMPLEX", "HIGH-CONSEQUENCE" was not used to depict any consequences brought about by the accident. It was only used to refer to the potential hazardous the oil industry may face in the future. Its bigger context is like this: Through the accident, BP has learnt a lot, so we will be more competent in handling those potential hazards.

For example:

(16) We have conducted a best-practice review of 21 organizations that use contractors in potentially high-consequence activities.

(17) In the upstream, we use systematic selection processes which include pre-contract quality, technical and health, safety, security and environment audits for certain potentially high-consequence activity.

There are more Engagement markers in the 2011 CEO statement than that in 2009, even though the frequency differences of both the contractive markers and expansive markers are not statistically significant. The following types of ENGAGEMENT are what the researchers found in the CEO statement of 2011, among which, the seventh is comparatively more frequent in the $2011 \mathrm{CEO}$ statement, and the difference is statistically significant $(p=.031)$.

First: disclaim/deny

(18) There were also studies of manatees, due to concern about whether manatees were affected by the spill. № manatees were observed in oiled surface waters. (The negation is used to clarify the consequences of the accident: It's not as serious as expected.)

Second: disclaim/counter-expect

(19) We recognize there is more to do, but we believe important progress was achieved during the year. (The word but, as a counter-expectation, is used to change the stakeholders negative perception on the company's capability in handling crisis.)

Third: proclaim/expect

(20) Of course, the changes being made to enhance the way we work are not limited to the Gulf Coast. (The expression of course is used to highlight the company's operation matches the stakeholders' expectation.)

Fourth: entertain/modal verbs

(21) We have set three clear priorities-safety must be enhanced, trust earned back, and greater value delivered to our shareholders. (The deontic must highlights the company's determination to remedy the disastrous consequences, and it also performs a hedging function, underlying BP's resolution but leaving options open for the possibility that the norms are not met.)

Fifth \& sixth: attribute \& entertain/appearance

(22) Data collection and analysis are ongoing, but preliminary analysis indicates that the effects on wildlife by the oil spill appear to be much less than initially feared. (The verbs indicate and appear are employed to open the dialogic space to alternative viewpoints.)

Seventh: entertain / first person pronoun + believe

(23) Over the long term, we believe these changes will help foster the development of expertise and reinforce accountability for managing risk. (The epistemic verb believe opens the dialogic space to alternative viewpoints, framing the CEO statement as a contingent and subjective proposal.)

\section{CONCLUSION}

What we have observed from the study suggests that CEO statement in a CSR report is actually a discursive activity where the leaders of the company take the opportunity to address the concerns of potential readers and defuse the criticisms. In face of a major environmental disaster, BP deploys interpersonal resources to portray itself as an indispensable provider of energy for the whole world, a survivor from the disaster, and a student who is good at learning from a lesson. All of these communicative goals were achieved with the help of Appraisal resources. In other words, through Appraisal resources, BP discursively construes its corporate identity and negotiates its relationship with their relevant publics.

\section{REFERENCES}

[1] Bakhtin, M. M. (1981). The Dialogic Imagination (translated by C. Emerson \& M. Holquist). Austin: University of Texas Press.

[2] Bakhtin, M. (1986). The problem of speech genres. In McGee, V. W. (trans.), Speech Genres and Other Late Essays. Austin: University of Texas Press.

[3] Bowen, H. R. (1953). Social Responsibilities of the Businessman. New York: Harper \& Row.

[4] Deegan, C., M. Rankin \& P. Voght. (2000). Firms' disclosure reactions to major social incidents: Australian evidence. Accounting Forum 24(1): 101-130.

[5] Iedema, R., S. Feez, and P. R. R. White. (1994). Media Literacy. Sydney, Disadvantaged Schools Program, NSW Department of School Education.

[6] Martin, J. \& P. White. (2005). The Language of Evaluation: Appraisal in English. London and New York: Palgrave Macmillan.

[7] Park, D., \& Berger, B. K. (2004). The presentation of CEOs in the press, 1990-2000: Increasing salience, positive valence, and a focus on competency and personal dimensions of image. Journal of Public Relations Research 16(1): 93-125. 
[8] Ullmann, A. (1985). Data in Search of a Theory: A Critical Examination of the Relationship Among Social Performance, Social Disclosure and Economic Performance of US Firms. Academy of Management Review 10(2): 540-557.

[9] Waldman, D. A., Siegel, D. S., \& Javidan, M. (2006). Components of CEO transformational leadership and corporate social responsibility. Journal of Management Studies 43(8): 1703-1725.

[10] White, P. (2001). An introductory tour through Appraisal theory (word processor version). http://www.grammatics.com/appraisal (accessed 08/29/12).

Dongmei Wang was born in Changchun, Jilin, China in 1977. She received her MA degree in Applied Linguistics from Jilin University in 2002. She is currently a lecturer in the Department of Foreign Languages, Dalian University of Technology, Dalian, China. Her academic research mainly focuses on systemic functional linguistics and discourse analysis.

Xiaowei Guan was born in Shenyang, China in 1979. She received her PH.D. in machine translation from Dalian University of Technology, China, in 2009. She is currently a lecturer in the School of Foreign Languages, Dalian University of Technology, Dalian, China. Her research interests include machine translation and natural language processing, E-C and C-E translation and contrast. 